\title{
Cerebrospinal fluid pressure in pyogenic meningitis
}

\author{
R A MINNS, H M ENGLEMAN, AND H STIRLING \\ Department of Neurology, Royal Hospital for Sick Children, Edinburgh
}

SUMMARY The pressure of cerebrospinal fluid taken at lumbar puncture was recorded objectively by strain gauge pressure measurement in 35 infants and children with pyogenic meningitis. Raised pressures were found in 33 children. The median pressure was $15 \mathrm{~mm} \mathrm{Hg}$ (range 4-70 $\mathrm{mm} \mathrm{Hg}$ ) in all age groups. The pressure level varied throughout the infection, but a higher median pressure $(19 \mathrm{~mm} \mathrm{Hg})$ was found when this was measured on the day of admission. The clinical features of the meningitis in these patients suggest that many of the presenting symptoms and signs are those of pressure. These results show that high pressure is frequently present in childhood meningitis, not just in those who die from cones or who have radiological evidence of hydrocephalus. We conclude that raised cerebrospinal fluid pressure is a frequent accompaniment of childhood meningitis and may need treatment in its own right and is therefore one further important factor influencing the course and outcome of childhood meningitis.

The outcome from bacterial meningitis in infancy and childhood has not significantly improved over the last 15 years. In a series from Boston there was a mortality of $6.4 \%$ for all types of meningitis in infancy and childhood. ${ }^{1} \mathrm{~A}$ recent report from the United Kingdom found an $8.6 \%$ mortality from bacterial meningitis in the first year of life. ${ }^{2}$

One possible cause for therapeutic failure and this morbidity and mortality may be the failure to recognise and treat accompanying raised intracranial pressure with its effect of impairing cerebral blood flow with subsequent ischaemia. Brain swelling has been recognised as an important contributing factor to the mortality and morbidity in some cases of pyogenic meningitis. ${ }^{3}$ It has been suggested that monitoring cerebrospinal fluid pressure and aggressive treatment could be crucial to survival in selected cases of meningitis which had clinical features of raised intracranial pressure. ${ }^{4}$ Evidence, however, for raised pressure in pyogenic meningitis has relied largely upon necropsy reports of brain swelling and cones. In a review of the literature Addy deduced that coning may contribute to the outcome in perhaps $30 \%$ or more deaths from meningitis. 5

Direct measurement has been undertaken in severely ill ventilated children with infections of the central nervous system, 11 of whom had meningitis. ${ }^{6}$ For these 11 comatose patients the maximum intracranial pressure was $47 \mathrm{~mm} \mathrm{Hg}$ and the minimum cerebral perfusion pressure $30 \mathrm{~mm} \mathrm{Hg}$. Only four were normal on long term follow up and the author considered a cerebral perfusion pressure greater than $30 \mathrm{~mm} \mathrm{Hg}$ a significant pointer to survival.

This paper is a descriptive account of the intracranial pressure (and the cerebral perfusion pressure) from direct lumbar puncture recordings, with a non-fluid displacement method, in 35 infants and children with different types of pyogenic meningitis.

\section{Patients and methods}

The patients were all treated at the Royal Hospital for Sick Children, Edinburgh, in the neurology unit. There were 35 children who had pressure in the lumbar cerebrospinal fluid measured in the course of pyogenic meningitis. Their median age was 10 months ranging from 1 month to 13 years; 18 were infants. There were 23 boys and 12 girls. The patients included in this study were both selected and unselected: they were selected in that the neurology unit at this hospital does not see all admitted patients with pyogenic meningitis, and frequently only sees pyogenic meningitis with neurological complications. Eight of these patients had already commenced antibiotic treatment when transferred from another hospital or unit. They were unselected in that all available pressure recordings of lumbar cerebrospinal fluid obtained in patients with pyogenic meningitis over the last eight years were included in this study. 
From the onset of symptoms until pressure recording of lumbar cerebrospinal fluid, there was a median of three days (range of 0.5 days to 21 days). This pressure recording was the first lumbar puncture (that is, in which the diagnosis of meningitis was made) in 28 cases and was a subsequent lumbar puncture recording in seven patients. The time between admission to hospital and this pressure recording ranged from 0-13 days. Twenty two of the 35 patients' recordings were from lumbar puncture on the day of admission.

\section{TECHNIQUE}

The cerebrospinal fluid pressure recordings were obtained at the time of lumbar puncture. We used a non-displacement method of measuring the cerebrospinal fluid pressure by connecting a strain gauge pressure transducer (attached to a three way tap) to the end of the spinal needle when the stilette had been removed and the cerebrospinal fluid had reached the mouth of the needle. ${ }^{7}$ The presence of a pulse wave verified the position of the spinal needle and showed the respiratory and cardiac component of the pressure wave.

The strain gauge transducer was calibrated before procedure with a sphygmomanometer over a range of $0-50 \mathrm{~mm} \mathrm{Hg}$. The transducer was then sterilised in a $2 \%$ solution of glutaraldehyde (Cidex). The signal from the transducer was written out as a permanent record on a physiological pen recorder. A minute or more of recording was obtained while the patient was permitted to relax a little with slightly reduced flexion, with the head and neck in a neutral position and no undue abdominal compression. After a few minutes, the patient relaxed and the pressure dropped to its true height. At this level with free communication in the cerebrospinal fluid spaces, the pressure of the lumbar cerebrospinal fluid reflected the intracranial pressure.

These pressure recordings of lumbar cerebrospinal fluid were only obtained in situations where a lumbar puncture was indicated and clearly would not be obtained where there were absolute contraindications to doing a lumbar puncture in the first place (such as a coma, decerebration, papilloedema, retinal haemorrhages, evidence of space occupation, etc) without first scanning the patient. This method of lumbar pressure recording was both more accurate and potentially safer than the older open ended manometric methods. It was more accurate in that cerebrospinal fluid was not displaced from a closed craniovertebral axis into a capillary column in order to measure the pressure. It was potentially safer in that if high pressure was found, then without removing cerebrospinal fluid, mannitol $(7 \mathrm{ml} / \mathrm{kg}$ of $20 \%$ solution) and frusemide $(1 \mathrm{mg} / \mathrm{kg})$ could be given with an immediate effect on the cerebrospinal fluid pressure.

The signs and symptoms of raised intracranial pressure are known to be unreliable, variable, unusual, and even absent. ${ }^{8} \mathrm{~A}$ tense anterior fontanelle does not show the extent to which the pressure is raised, ${ }^{9}$ whereas direct measurement is unequivocal, therefore if coma was present (to the extent of failure to localise pain) a computed tomogram was performed to determine if the basal cisterns were open and there was no space occupation. Should a subsequent lumbar puncture be necessary in the course of treatment of meningitis, or if intrathecal antibiotics were being used, then lumbar puncture pressures were recorded on each occasion.

Before lumbar puncture a blood pressure measurement was obtained by conventional sphygmomanometer cuff on the upper limb. This allowed calculation of a single cerebral perfusion pressure value using the classical method-that is, by subtraction of the mean cerebrospinal fluid pressure from the mean systemic blood pressure.

\section{Results}

A positive bacteriological identification of the infecting organism was made in 26 cases: seven were due to meningococcal meningitis, 11 to Haemophilus influenzae, four to pneumococcus, one to tuberculous meningitis, one patient had two organisms (meningococcus and haemophilus), one a pasteurella organism, and one a coliform. Four further cases were partially treated on admission and no organism cultured. Five further cases were clinically recognised as meningococcal without bacteriological confirmation.

The clinical presentation of the symptoms and signs that were apparent at any stage during the course of the pyogenic meningitis are shown in table 1.

Brain imaging by either ultrasound scanning or computed tomography was not available on all patients at a consistent time in the course of the meningitis but on 10 occasions there were abnormal imaging results in the form of oedema, dilatation of the lateral and third ventricles, subdural effusions or collections and tight ventricles from oedema. An increase in the size of the subarachnoid space together with an increased echogenicity of the interhemispheric convolutions, and increased parenchymal echogenicity as previously described, ${ }^{10}$ was a not infrequent appearance.

Fifteen of these 35 patients had the pressure of their lumbar cerebrospinal fluid measured while having mannitol or immediately after the adminis- 
Table 1 Frequency of symptoms and signs in 35 cases of pyogenic meningitis

\begin{tabular}{lc}
\hline & No of children \\
\hline Symptoms: & \\
Fever & 31 \\
Headache/irritability & 29 \\
Vomiting & 22 \\
Anorexia & 17 \\
Seizure & 14 \\
Lethargy & 10 \\
Diarrhoea & 9 \\
Photophobia & 5 \\
Stridor & 4 \\
Signs: & \\
Neck stiffness & 22 \\
Drowsiness & 21 \\
Respiratory dysfunction & 19 \\
Abnormal tone & 18 \\
Pallor & 18 \\
Tense anterior fontanelle & 13 \\
Rash & 12 \\
Opisthotonos & 11 \\
Squint & 8 \\
Positive Kernig's sign & 8 \\
Papilloedema & 8 \\
\hline
\end{tabular}

tration of mannitol. Twenty did not have mannitol at the time of this lumbar puncture recording. Only two of these 35 children had an intracranial pressure measurement that could be considered in the normal range for age (as defined in table 2). The normal range of pressure was calculated by an extensive literature search and the upper limit defined for neonates, infants, children (up to 14 years), and adults. On this basis, only two children had intracranial pressure measurements in the normal range and one of these was on the 17th day of the child's illness, three days after admission to hospital. The other was in the intensive care unit and it was seven days after admission when this pressure recording was obtained.

The median and range of lumbar cerebrospinal fluid pressure measurements are shown in table 3. These values are higher than the expected mean cerebrospinal fluid pressure values in normal individuals. The 35 cerebrospinal fluid pressure values from 35 children with pyogenic meningitis are contrasted with normal intracranial pressure upper limits extracted from the literature and shown in fig 1. Blood pressure measurement before lumbar

Table 2 Mean upper limit of normal intracranial pressure derived from studies where intracranial pressure was objectively measured

\begin{tabular}{|c|c|c|c|}
\hline & $\begin{array}{l}\text { Normal pressure } \\
\text { ( } \mathrm{mm} \mathrm{Hg})\end{array}$ & Method & $\begin{array}{l}\text { Mean upper normal limit } \\
(\mathrm{mm} \mathrm{Hg})\end{array}$ \\
\hline \multicolumn{4}{|l|}{ Neonates: } \\
\hline Welch $1980^{11}$ & $0 \cdot 29-4 \cdot 41$ & Fontanometry & \\
\hline Welch $1978^{12}$ & $<2.94$ & Fontanometry & \\
\hline Kaiser and Whitelaw $1986^{13}$ & $2.8(1.4)(\mathrm{SD})$ & Lumbar puncture & \\
\hline Gerlach et al $1967^{14}$ & $0.74-1.03$ & Lumbar puncture & $<3 \cdot 5$ \\
\hline \multicolumn{4}{|l|}{ Infants: } \\
\hline Welch $1980^{11}$ & $1 \cdot 84-12 \cdot 15$ & Fontanometry & \\
\hline Gaab et al $1980^{15}$ & 5 (2) (SD) & Fontanometry & \\
\hline von Wild and Porksen $1980^{16}$ & $-2-5$ & Fontanometry & \\
\hline Sidbury $1920^{17}$ & $2 \cdot 21-5 \cdot 15$ & Lumbar puncture & \\
\hline Levinson $1928^{18}$ & $1 \cdot 47-5 \cdot 15$ & Lumbar puncture & $<5.8$ \\
\hline Munro $1928^{19}$ & $2 \cdot 12-5 \cdot 88$ & Lumbar puncture & \\
\hline \multicolumn{4}{|l|}{ Children: } \\
\hline Quincke $1891^{20}$ & $2 \cdot 94-4 \cdot 41$ & Lumbar puncture & \\
\hline Levinson $1923^{21}$ & $3 \cdot 31-6 \cdot 99$ & Lumbar puncture & \\
\hline Levinson $1928^{18}$ & $2 \cdot 94-5.88$ & Lumbar puncture & \\
\hline Lups and Haan $1954^{22}$ & $2 \cdot 94-7.35$ & Lumbar puncture & $<6.4$ \\
\hline Gerlach et al $1967^{14}$ & $2 \cdot 94-7 \cdot 35$ & Lumbar puncture & \\
\hline \multicolumn{4}{|l|}{ Adults: } \\
\hline Merritt and Fremont-Smith $1937^{23}$ & $<13 \cdot 24$ & Lumbar puncture & \\
\hline Masserman $1934^{24}$ & $10.9(2.5)(\mathrm{SD})$ & Lumbar puncture & \\
\hline Masserman $1935^{25}$ & $11 \cdot 1(2 \cdot 1)(\mathrm{SD})$ & Lumbar puncture & \\
\hline Spina-Franca $1963^{26}$ & $3-14 \cdot 5$ & Cisternal puncture & \\
\hline Tourtellotte et al $1964^{27}$ & $11(2 \cdot 4)(\mathrm{SD})$ & Lumbar puncture & $<15 \cdot 3$ \\
\hline Gilland et al $1974^{28}$ & $11.5(2.6)(\mathrm{SD})$ & Lumbar puncture & \\
\hline Ekstedt $1978^{29}$ & $10.3(1.5)(\mathrm{SD})$ & Lumbar puncture & \\
\hline Ferris $1941^{30}$ & $<17.6$ & Lumbar puncture & \\
\hline
\end{tabular}


Table 3 Median and range of cerebrospinal fluid pressures in patients with pyogenic meningitis

\begin{tabular}{|c|c|c|}
\hline & $\begin{array}{l}\text { No } \\
\text { of patients }\end{array}$ & $\begin{array}{l}\text { Median (range) } \\
\text { cerebrospinal } \\
\text { fluid pressure } \\
\text { (mm } \mathrm{Hg})\end{array}$ \\
\hline All patients & 35 & $15(4-70)$ \\
\hline At diagnostic lumbar puncture & 28 & $15(8-70)$ \\
\hline Aged $<1$ year & 18 & $15(4-28)$ \\
\hline Aged $>1$ year & 17 & $15(5-70)$ \\
\hline $\begin{array}{l}\text { Aged }>1 \text { year and at } \\
\text { diagnostic lumbar puncture } \\
\text { Aged }>1 \text { year with lumbar } \\
\text { puncture on day of } \\
\text { admission }\end{array}$ & 15 & $15(8-70)$ \\
\hline
\end{tabular}

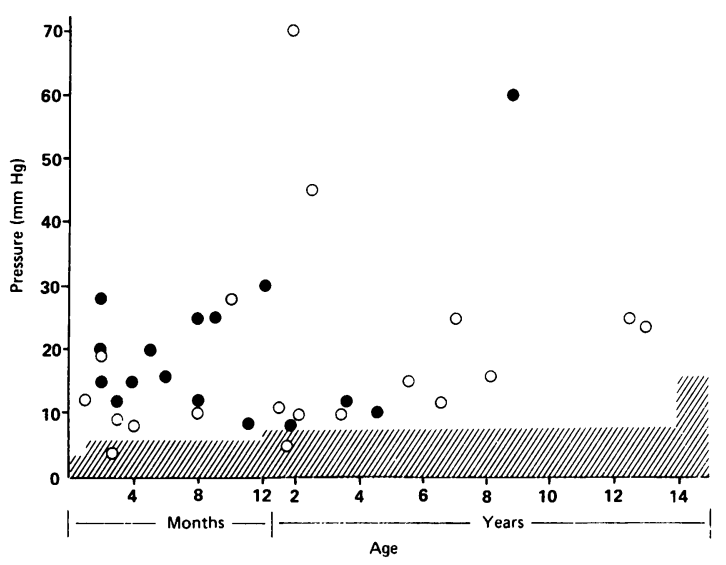

Fig 1 Cerebrospinal fluid pressure measurements from 35 children with pyogenic meningitis compared with the normal upper limits as previously defined.

(O)=pressure level without mannitol. $(\mathrm{O})=$ pressure level after mannitol plus frusemide.

puncture was available on 33 children. The mean (SD) systemic blood pressure was 80.5 (11.9) $\mathrm{mm} \mathrm{Hg}$. The cerebral perfusion pressure was calculated individually on 33 children and the median pressure was $65 \mathrm{~mm} \mathrm{Hg}$ (range 8-88 $\mathrm{mm} \mathrm{Hg}$ ) when a raised cerebrospinal fluid pressure was present. There was no correlation between the levels of pressure and the cell counts, or cerebrospinal fluid protein concentrations.

The outcome categories are those suggested by Seshia et al with five grades of outcome: 1, normal; 2 , mild handicap as suggested by minimal alterations of tone, reflexes, an isolated cranial nerve palsy, mild weakness or ataxia, moderate handicap; 3 , moderate weakness or ataxia, behaviour disturbance, cranial nerve involvement; 4 , severe handicap, severe weakness or ataxia, tetraplegia; and 5, death. ${ }^{31}$ In terms of development state, grade 1 was normal, grade 2 was mild handicap, grade 3 was moderate handicap, grade 4 was profound handicap, and grade 5 was death.

There were no deaths in this series. Twenty four of these children with pyogenic meningitis were neurodevelopmentally normal at the time of follow up, and eight had a minimal handicap (one was delayed slightly in development, one had mild hypotonia, three had squints, two had mild deafness, and one had controlled seizures). Three children suffered severe handicap (one was deaf, blind and mentally handicapped with hydrocephalus, a second was hydrocephalic, deaf, blind, had seizures and cerebral palsy, and the third had severe cerebral palsy, epilepsy, and choreoathetosis). The period of follow up was from one month to six years 10 months, a median follow up of one year and one month. As might be expected there was no correlation between mean intracranial pressure or cerebral perfusion pressure measurements and outcome, nor between the cells or protein in the cerebrospinal fluid and outcome. In particular, there was no correlation of age with outcome.

\section{Discussion}

A single pressure recording of lumbar cerebrospinal fluid was made in each of the 35 children with pyogenic meningitis. These values were raised in 33 of the 35 cases when compared with normal pressures ascertained by an exhaustive literature search of papers where the cerebrospinal fluid pressure was directly measured.

This rise in lumbar cerebrospinal fluid pressure was despite the fact that some of these lumbar pressure recordings were measured at diagnostic lumbar puncture, after mannitol administration, or after commencement of treatment. The median pressure of lumbar cerebrospinal fluid was $15 \mathrm{~mm}$ $\mathrm{Hg}(4-70 \mathrm{~mm} \mathrm{Hg})$ with a slightly higher value for meningitis after 12 months of age when children had a pressure recording early in the course of their meningitis of $19 \mathrm{~mm} \mathrm{Hg}(8-70 \mathrm{~mm} \mathrm{Hg})$. The range of this pressure rise was up to $70 \mathrm{~mm} \mathrm{Hg}$ in one case (patient not given mannitol). It could reasonably be assumed that the 15 patients who had their cerebrospinal fluid pressures measured immediately after mannitol would have had considerably higher cerebrospinal fluid pressures had mannitol not been given. Daily or sequential pressure measurements were obtained in only a few children and apart from the frequent finding of raised pressure early in meningitis, raised pressures were frequently found at other times and could vary significantly from day to day. 
Although the normal values are quoted in the literature, most clinicians use as a rule of thumb a normal intracranial pressure of adults and older children as being less than $10 \mathrm{~mm} \mathrm{Hg}$ with values of $10-20 \mathrm{~mm} \mathrm{Hg}$ thought to be raised but not requiring any treatment and those values above $20 \mathrm{~mm} \mathrm{Hg}$ as being unequivocally raised. In this whole series 13 cases had intracranial pressure levels of $20 \mathrm{~mm} \mathrm{Hg}$ or more and in children over the age of 12 months, all but two had values in excess of $10 \mathrm{~mm} \mathrm{Hg}$.

Simultaneous blood pressure measurements allowed a cerebral perfusion pressure to be calculated but despite the high cerebrospinal fluid pressure, the cerebral perfusion pressure values in only two children were below acceptable levels of $30 \mathrm{~mm}$ $\mathrm{Hg}$. It is suggested that cerebral autoregulatory mechanisms are non-functioning in severe infections of the central nervous system in which case the cerebral blood flow is passively dependent on the systemic blood pressure maintaining a cerebral perfusion pressure. The high cerebral perfusion pressures (despite the fact that they are single measurements) in this study reflect a Cushing effect of an increase in systemic blood pressure secondary to raised intracranial pressure, which is a compensatory mechanism which maintains an adequate perfusion pressure despite a raised intracranial pressure.

'C waves' were originally described as spontaneous fluctuations in the intracranial pressure signal occurring at $6 /$ minute (range 4-8) ${ }^{32}$ ' $\mathrm{C}$ waves' have not previously been reported in meningitis but occurred in eight patients in our series (fig 2). It has been postulated that they reflect Traube-Hering-Mayer vasomotor waves that occur in the systemic blood pressure. They are part of the Cushing phenomena and occur with raised intracranial pressure. An intact Cushing response is a protective mechanism to maintain cerebral perfusion pressure and the frequent observation of these ' $\mathrm{C}$ waves' in our

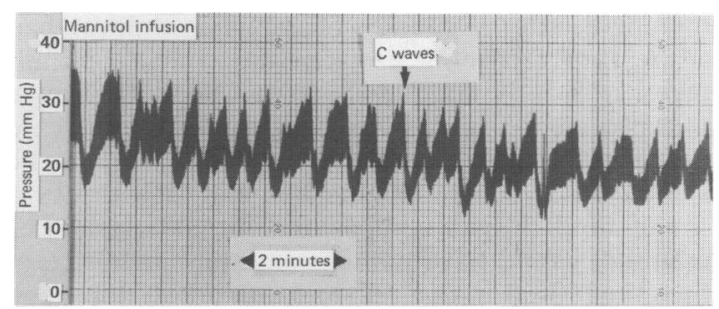

Fig 2 A 12 month old boy with Haemophilus influenzae infection who was given mannitol during recording of cerebrospinal fluid pressure at lumbar puncture, with a slow return of the pressure from $30 \mathrm{~mm} \mathrm{Hg}$ to normal, and who required intravenous frusemide. The recording shows typical ' $C$ waves' with a ramped appearance. recordings is consistent with there being a high cerebral perfusion pressure.

\section{THEORETICAL REASONS FOR RAISED PRESSURE}

These results suggest that a raised cerebrospinal fluid pressure is much more common than has been suggested by the number of meningitic deaths from pressure coning. There are several possible theoretical reasons to explain rises of the cerebrospinal fluid pressure: (a) arachnoid granulations become occluded; (b) constriction and strangulation of cerebral veins; (c) cerebritis; and (d) a generalised inflammatory brain oedema; (e) adhesive formation at the base of the brain; (f) inappropriate secretion of antidiuretic hormone; ( $g$ ) subdural effusions or haematoma or abscesses; (h) major seizures or status epilepticus ${ }^{33}$; and (i) an increase in cerebrospinal fluid production.

We have observed that the response to mannitol varies. In some patients the raised pressure may take 25 minutes to return to normal values, while in other cases (fig 3 ) the response is more dramatic, suggesting that different pathological mechanisms are responsible for the oedema or hydrocephalus in different patients. It is possible that more than one of the above mechanisms may be operative in any one patient. As there were only 15 patients who received mannitol, the precise intracranial pressure response in patients with pyogenic meningitis would require investigation in a larger series. No one type of organism resulted in pressure significantly different from another, that is, haemophilus, meningococcus, or pneumococcus were not more prone to higher pressures in this series.

CLINICAL FEATURES OF MENINGITIS AND PRESSURE Many of the clinical features in this series (tense

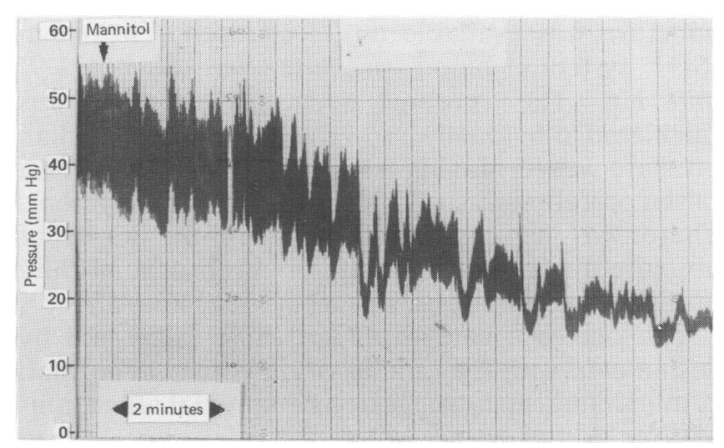

Fig 3 A 21/2 year old boy with meningococcal meningitis and septicaemia whose cerebrospinal fluid pressure at lumbar puncture decreased from $43 \mathrm{~mm} \mathrm{Hg}$ to normal values in approximately 12 minutes with mannitol infusion. 
fontanelle, squint, neck stiffness, posturing, vital sign abnormalities, opisthotonos, and papilloedema) are in fact signs of raised intracranial pressure, although they are traditionally thought of as signs of meningeal infection. Our observation of frequent raised pressure would confirm some of the clinical features as pressure signs more than infection signs.

\section{IMPORTANCE OF RAISED PRESSURE (IMMEDIATE AND LONG TERM)}

The question of the importance of raised cerebrospinal fluid pressure is more difficult to prove. In the short term these children on presentation are frequently irritable, resent handling, have vital sign abnormalities, pupillary abnormalities, etc, and after the administration of mannitol there is almost always an improvement in these signs and the patients' general responsiveness, confirming that it is often the pressure which is responsible for the clinical picture. Observations similar to these were made by Williams et al who used hypertonic intravenous urea and found a dramatic improvement in respiration, conscious state, pupillary signs, and cessation of fits. ${ }^{3}$ There were no children who developed subdural effusions in this series as a result of a rapid diminution of brain volume from mannitol and frusemide.

In the long term all that can be said is that treatment of raised intracranial pressure may lessen the neurological complications of meningitis. It would not be possible having measured a raised cerebrospinal fluid pressure, not to do anything about it in an individual child, and yet there seems little hope of proving its importance without a controlled trial of treatment for raised pressure.

As there are multiple factors likely to influence outcome, one would not expect with 35 patients to see a statistical association between the level of intracranial pressure (or cerebral perfusion pressure) and outcome. What is important, however, is that there was no mortality in this group and the overall morbidity and mortality for meningitis was less than expected from the current literature. Eleven children $(31 \%)$ in this series had some sequelae, eight of these were minimal (four with squints, two with mild hearing impairments, one mildly clumsy, one with two fits within one month of completing treatment), and three children had severe neurological deficits $(8 \cdot 6 \%)$. The period to follow up, however, in some cases was quite short and ranged from one month to six years and 10 months with a median of one year one month. Therefore, mild neurological sequelae may not yet be apparent in some of these younger children (for example, clumsiness).
The effect of raised intracranial pressure is to reduce cerebral perfusion pressure and produce ischaemia as well as produce brain shifts and cones. It may be that management of raised pressure in meningitis will have a more dramatic effect on mortality than morbidity as the cerebral perfusion pressure was largely preserved in these patients.

Postmortem examinations of children who had meningitis have shown evidence of pressure (with brain stem compression, swollen oedematous brain, diminished ventricular size, bilateral grooving of the uncal gyri, and rostrocaudal brain stem compression) and scanning has shown hydrocephalus or oedema. Our results show the very frequent accompaniment of raised cerebrospinal fluid pressure with pyogenic meningitis, but our hypothesis remains, that raised pressure is but one important factor influencing the outcome of childhood meningitis.

The authors gratefully acknowledge financial support from Action Research for the Crippled Child.

\section{References}

1 McKracken GH Jr. Management of bacterial meningitis in infants and children. Current status and future prospects. $A m J$ Med 1984;76:215-23.

2 Karim Centre for Meningitis Research. Report on mortality from meningitis in the first year of life in $U K$. London: British Paediatric Association, 1988.

3 Williams CPS, Swanson AG, Chapman JT. Brain swelling with acute purulent meningitis. Pediatrics 1964;55:220-7.

4 Nugent SK, Bausher JA, Moxon ER, Rogers MC. Raised intracranial pressure: its management in Neisseria meningitidis meningoencephalitis. Am J Dis Child 1979;133:260-2.

5 Addy DP. When not to do a lumbar puncture. Arch Dis Child 1987;62:873-5.

${ }^{6}$ Goiten KJ, Tamir I. Cerebral perfusion pressure in central nervous system infections of infancy and childhood. $J$ Pediatr 1983;103:40-3.

7 Minns RA. Intracranial pressure monitoring. Arch Dis Child 1984;59:486-8.

${ }^{8}$ Kirkpatrick M, Engleman H, Minns RA. Symptoms and signs of progressive hydrocephalus. Arch Dis Child 1989;64:124-8.

9 Kaiser AM, Whitelaw AGL. Intracranial pressure estimation by palpation of the anterior fontanelle. Arch Dis Child 1987;62: 516-7.

10 Angonese I, Zorzi C. Transfontanelle cerebral sonography utilization in bacterial meningitis of the neonate and nursing baby. Journal of Pediatric Neurosciences 1986;2:174-80.

1 Welch K. The intracranial pressure in infants. $J$ Neurosurg 1980;52:693-9.

12 Welch K. Normal pressure hydrocephalus in infants and children: a re-appraisal. Z Kinderchir 1978;25:319-24.

13 Kaiser AM, Whitelaw AGL. Normal cerebrospinal fluid pressure in the newborn. Neuropediatrics 1986;17:100-2.

14 Gerlach J, Jenson HP, Koos W, Kraus H. Pediatrische Neurochirurgie mit klinisch Diagnostik and Differentialdiagnostik in Pediatrie und Neurologie. Stuttgart: Georg Thieme Verlag, 1967:139.

15 Gaab MR, Sorenson N, Brawanski A, Bushe KA. Wodarz R. Non-invasive intracranial pressure monitoring by fontanometry. Z Kinderchir 1980;31:339-47.

16 von Wild K. Porksen C. Non-invasive technique for monitoring intracranial pressure via the fontanelle in premature infants and newborns with hydrocephalus. Z Kinderchir 1980;31:348-53. 
17 Sidbury JB. The importance of lumbar puncture haemorrhage of the newborn. Arch Pediatr 1920;37:545-53.

${ }^{18}$ Levinson A. Cerebrospinal fluid in infants and in children. Am J Dis Child 1928;36:799-818.

19 Munro D. Cerebrospinal fluid pressure in the newborn. JAMA 1928;90:1688-9.

${ }^{20}$ Quincke H. Uber Hydrocephalus. Verhandlungen Congresses Innere Medizin 1891;10:321-40.

${ }^{21}$ Levinson A. Cerebrospinal fluid in health and in disease. 2nd ed. St Louis: CV Mosby, 1923:87-90.

22 Lups S, Haan AMFH. The cerebrospinal fluid. Amsterdam: Elsevier, 1954:31.

${ }^{23}$ Merritt HH, Fremont-Smith F. The cerebrospinal fluid. Philadelphia: WB Saunders,1937:333.

${ }^{24}$ Masserman JH. Cerebrospinal hydrodynamics IV: clinical experimental studies. Archives of Neurology and Psychiatry 1934;32:523-53.

25 Masserman JH. Cerebrospinal fluid hydrodynamics VI: correlation of the pressure of the cerebrospinal fluid with age, blood pressure and the pressure index. Archives of Neurology and Psychiatry 1935;34:564-6.

26 Spina-Franca A. Variacoes fisiologicas de pressao do liquido cefalorraqueano na cisterna magna. Arq Neuropisquiatr 1963; 21:19-24.
27 Tourtellotte WW, Haerer AF, Heller GL, Somers JE. Postlumbar puncture headaches. Springfield: Thomas, 1964.

${ }^{28}$ Gilland O, Tourtellotte WW, O'Tauma L, Henderson WG. Normal cerebrospinal fluid pressure. J Neurosurg 1974;40: 587-93.

29 Ekstedt J. CSF hydrodynamic studies in man. 2:normal hydrodynamic variables related to CSF pressure and flow. $J$ Neurol Neurosurg Psychiatry 1978;41:345-53.

30 Ferris EB. Objective measurement of relative intracranial blood flow in man with observations concerning hydrodynamics of the craniovertebral system. Archives of Neurology and Psychiatry 1941;46:377-401.

31 Seshia SS, Seshia MMK, Sachdeva RK. Coma in childhood. Dev Med Child Neurol 1977;19:614-28.

32 Lundberg N. Continuous recordings and control of ventricular fluid pressure in neurosurgical practice. Acta Psychiatrica et Neurologica Scandinavia 1960 (suppl 149);36:168-70.

${ }^{33}$ Minns RA, Brown JK. Intracranial pressure changes associated with childhood seizures. Dev Med Child Neurol 1978;20:561-9.

Correspondence to Dr RA Minns, Royal Hospital for Sick Children, 9 Sciennes Road, Edinburgh EH9 1LF.

Accepted 1 December 1988. 